\title{
Relation of glenohumeral and acromioclavicular joint destruction in rheumatoid shoulder. A 15 year follow up study
}

Janne T Lehtinen, Kalevi Kaarela, Eero A Belt, Hannu J Kautiainen, Markku J Kauppi, Matti U K Lehto studied at the Rheumatism Foundation Hospital, Heinola, Finland. The selection criteria, data collection strategy and details on the patients are described elsewhere. ${ }^{13}$ At the three year follow up 102 patients had RF positive and erosive RA. Subsequently, a total of 24 patients had died, and four patients failed to attend the 15 year follow up. Thus, 74 patients $(18$ men, 56 women) were the subjects of this study; the age at onset ranged from 17 to 66 , mean 41.9 (SD 12.0) years.

Radiographs of all the 148 shoulders were taken at the 15 year follow up as part of a radiographic survey study. The following standard positioning was used: patient supine, slightly turned $\left(20^{\circ}\right)$ to the imaged side, and the arm in external rotation, palm facing upwards. The same radiographer confirmed correct positioning and took radiographs by the standard technique. Erosive, rheumatoid involvement of $\mathrm{GH}$ and $\mathrm{AC}$ joints was assigned by the Larsen method on a scale of $0-5 .^{6}{ }^{14}$

JTL assessed the Larsen grades, however, in case of interpretation difficulties all the authors took part in the evaluation and the final decision. One GH joint arthroplasty had been performed and the preoperative radiograph 13 years from disease onset was assessed as Larsen grade 5 . No surgical procedures had been performed into the AC joints. We have earlier reported the nature of radiographic destruction separately for $\mathrm{GH}$ and AC joints; erosive involvement (Larsen grade $\geqslant 2$ ) was observed in $71 \mathrm{GH}$ joints and in $87 \mathrm{AC}$ joints in 148 shoulders. $^{47}$

Correlations were estimated by Spearman's coefficient method.

\section{Results}

Erosive, rheumatoid involvement (GH or AC joints) was observed in 96 of 148 (65\%; $95 \%$ confidence intervals (CI) $57 \%$ to $73 \%$ ) shoulders. Hand dominance had no influence on the destruction. Both $\mathrm{GH}$ and $\mathrm{AC}$ joints were eroded (Larsen grade $\geqslant 2)$ in 62 of $148(42 \%$; $34 \%$ to $50 \%$ ) shoulders. Both joints remained unaffected (Larsen grade 0 or 1) in 52 of 148 $(35 \% ; 27 \%$ to $43 \%)$ shoulders.

The 71 shoulders with erosive $\mathrm{GH}$ joint changes presented AC joint involvement in 62 ( $87 \% ; 77 \%$ to $94 \%$ ) cases. The 87 shoulders with AC joint erosions showed $\mathrm{GH}$ joint involvement in $62(71 \% ; 61 \%$ to $81 \%)$ cases. In $25(17 \% ; 11 \%$ to $23 \%)$ shoulders AC joint was affected without $\mathrm{GH}$ joint involvement and only $\mathrm{GH}$ joint affection was detected in nine $(6 \% ; 3 \%$ to $11 \%)$ shoulders.
Foundation Hospital, Heinola, Finland

Correspondence to: Dr Lehtinen, Kiuruntie 21 FIN-36200 Kangasala, Finland

Accepted for publication 10 November 1999
Methods

During the period $1973-1975$ a total of 121 patients with recent ( $<6$ months) RA were 

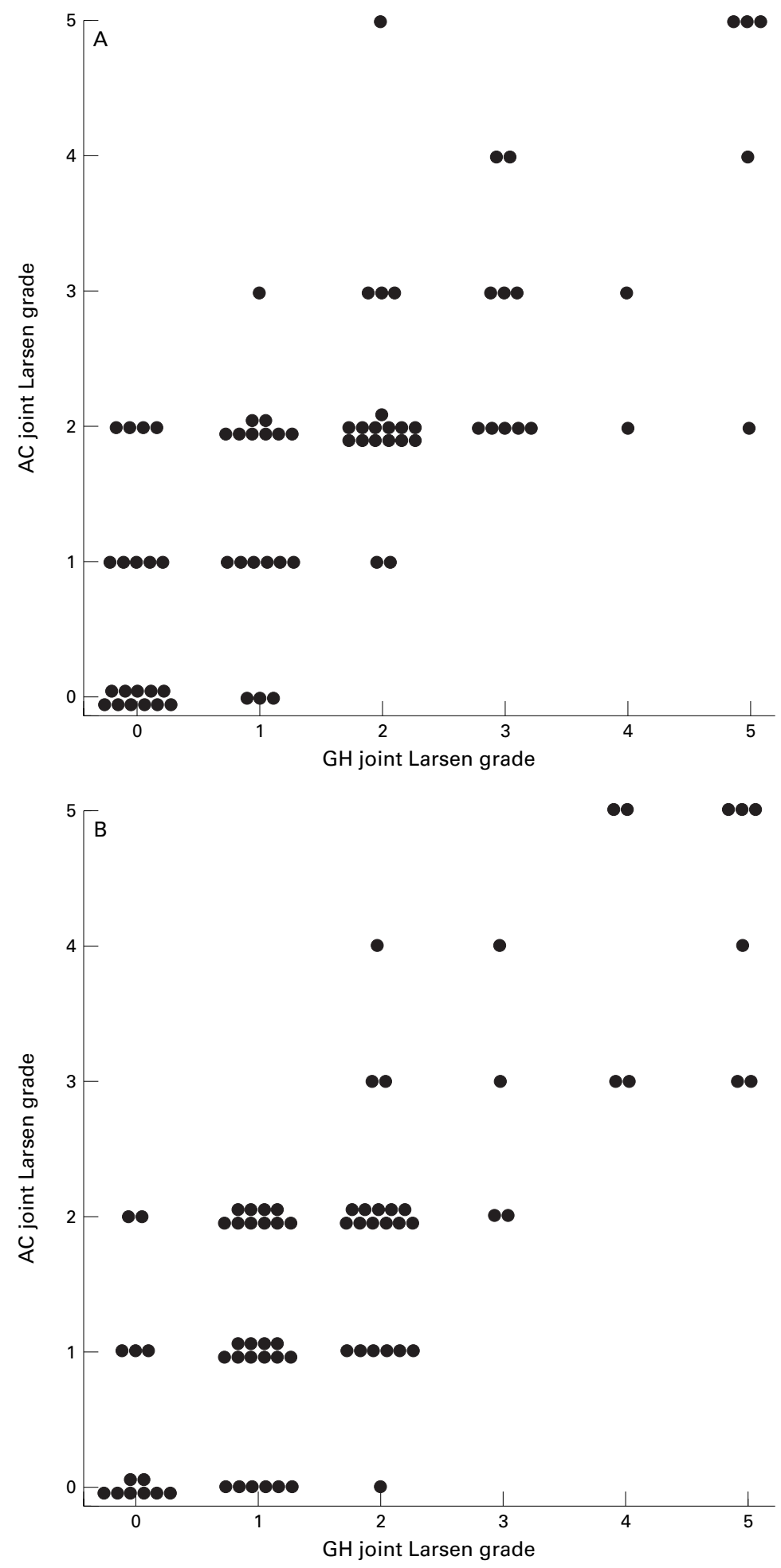

Figure 1 Distribution of right $(n=74)(A)$ and left $(n=74)(B)$ shoulders according to the $G H$ and $A C$ joint Larsen grading in $74 R A$ patients 15 years after disease onset.

Spearman's correlation coefficient between $\mathrm{GH}$ and $\mathrm{AC}$ joint destruction was $0.74,95 \% \mathrm{CI}$ 0.65 to 0.80 . The respective grades of destruction in both GH and AC joints are shown separately for right and left shoulders in figure 1 .

\section{Discussion}

In previous reports $\mathrm{AC}$ joint affection has been evaluated in shoulders with existing GH joint involvement. ${ }^{6}{ }^{10-12}$ Both Petersson and Cuomo

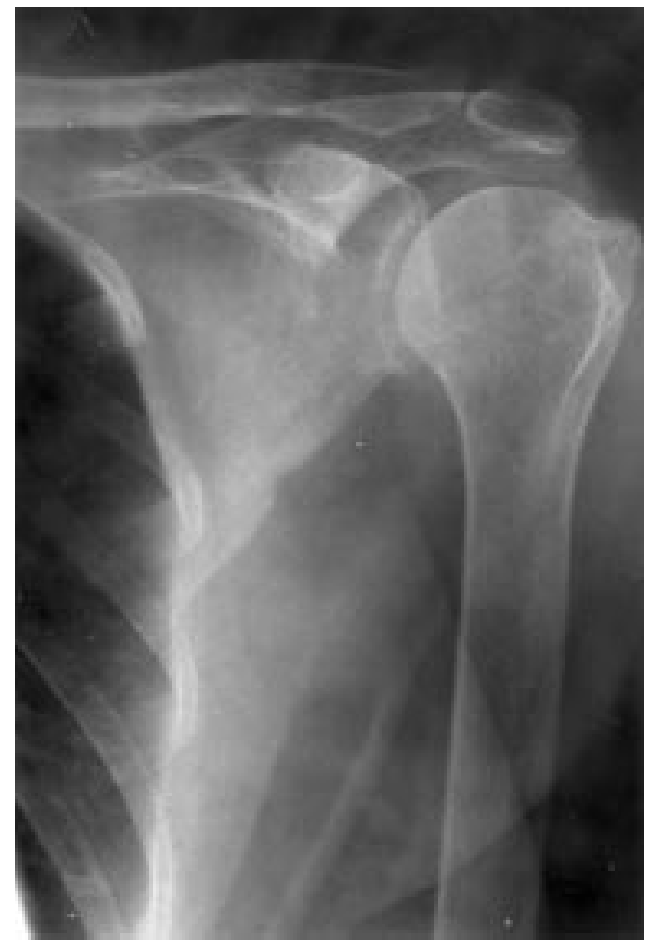

Figure 2 Radiograph of a rheumatoid shoulder. Erosions can be observed on the inferior joint margin of the AC joint: Larsen grade 2. The GH joint is unaffected: Larsen grade

have concluded that the AC joint is clinically involved in painful rheumatoid shoulders in about one third of the cases. ${ }^{611}$ Crossan and Vallance developed a radiographic staging method for rheumatoid shoulder that also describes simultaneous AC joint changes. ${ }^{12}$ According to our results AC joint is involved more frequently than the $\mathrm{GH}$ joint. In our material the shoulders with minor erosions on the AC joint, did not have any or had only slight involvement in $\mathrm{GH}$ joints (fig 2). At early stages of rheumatoid shoulder destruction of the AC joint seems to predominate. The similar early involvement of AC joint has been reported by Jones and Watt as well. ${ }^{15}$ Dijkstra et al found radiographic changes in the $\mathrm{GH}$ joint more than twice the amount of AC changes using their own grading method. ${ }^{8}$ This method assesses the joints giving five grades of destruction for $\mathrm{GH}$ but only three grades for AC joint, therefore it cannot be directly compared with the Larsen method. ${ }^{6814}$

Late affection of $\mathrm{GH}$ joint is reported in the literature. ${ }^{16}$ Although the GH joint was less often affected in our study, severe destruction occurred there more commonly than in the more frequently affected AC joint. ${ }^{4}{ }^{7}$ Once GH joint becomes involved, the erosive process seems to be often progressive and may sometimes rapidly lead to an extensive destruction, whereas minor erosions on the AC joint do not seem to predict rapid destruction of the joint. However, the most severe AC joint changes were seen in shoulders with totally destroyed GH joints (fig 3). Streda's finding that $\mathrm{AC}$ joint destruction does not seem to have any relation with the degree of changes in the $\mathrm{GH}$ joint is strongly controversial to our 


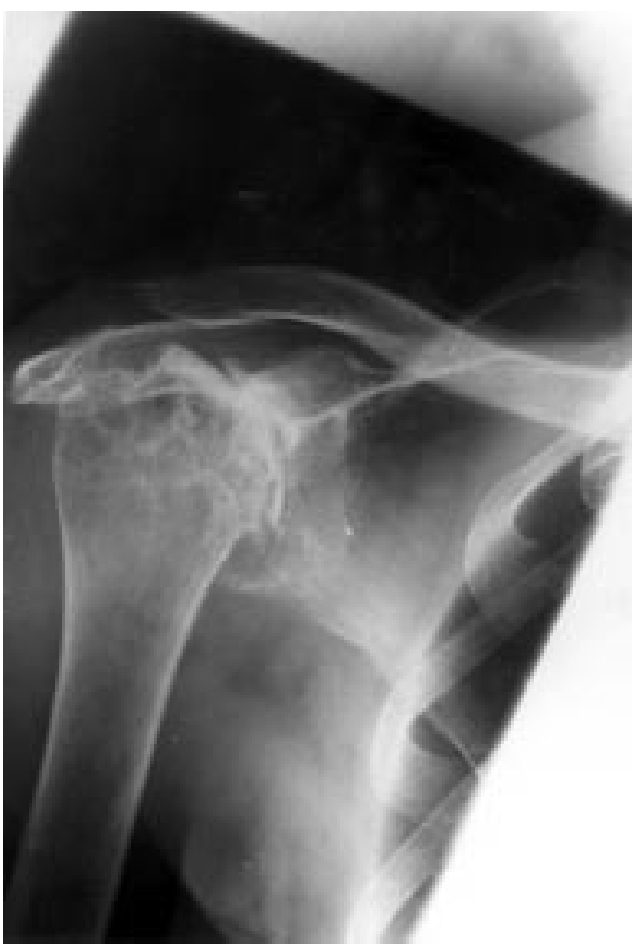

Figure 3 Radiograph of a rheumatoid shoulder. Extensive erosions have destroyed the distal clavicle and the articular surface of acromion. The AC joint space appears widened: Larsen grade 5. Erosive process has destroyed articular surfaces of the humerus and the glenoid. Gross bony deformation can be observed in the GH joint: Larsen grade 5.

findings. ${ }^{9}$ In our material only one shoulder had severely destructed AC joint (Larsen grade 5) with early destruction (Larsen grade 2) in the $\mathrm{GH}$ joint. The correlation between destruction in GH and AC joint is strongly supported by our findings, allthough the progression may differ in individual cases.

In this prospective radiographic 15 year follow up survey erosive involvement of the AC joint was more frequent than that of the $\mathrm{GH}$ joint. The AC joint is a possible site of pain before erosive involvement of the $\mathrm{GH}$ joint. However, most often $\mathrm{AC}$ and $\mathrm{GH}$ joints were eroded together. In case of early erosions on the AC joint the $\mathrm{GH}$ joint is also at risk to be affected. Solitary GH joint affection was the most uncommon type of involvement of the rheumatoid shoulder. This should be taken into account in clinical practice when planning optimal treatment for painful rheumatoid shoulder.

1 Bjelle A. Epidemiology of shoulder problems. Baillieres Clin Rheumatol 1989;3:437-51.

2 Petersson CJ. Painful shoulders in patients with rheumatoid arthritis. Scand J Rheumatol 1986;15:275-9.

3 Kuper H, van Leeuwen M, van Riel P, Prevoo M, Houtman PM, van Rijswik M. Radiographic damage in large joints in early rheumatoid arthritis. Br J Rheumatol 1994;33 (suppl 1):106.

4 Lehtinen JT, Kaarela K, Kauppi MJ, Belt EA, Kautiainen HJ, MUK Lehto. Incidence of glenohumeral joint involvement in seropositive rheumatoid arthritis. A 15 year endpoint study. J Rheumatol (in press).

5 Ennevaara K. Painful shoulder joint in rheumatoid arthritis. Acta Rheumatol Scand 1967 (suppl 11):44-55.

6 Petersson CJ. The acromioclavicular joint in rheumatoid arthritis. Clin Orthop 1987;223:86-93.

7 Lehtinen JT, Kaarela K, Kauppi MJ, Kautiainen HJ, Belt EA, Lehto MUK. Incidence of acromioclavicular joint involvement in rheumatoid arthritis. A 15 year endpoint study. J Rheumatol 1999;26:1239-41.

8 Dijkstra J, Dijkstra PF, van der Klundert W. Rheumatoid arthritis of the shoulder. Fortschr Röntgenstr 1985;142: $179-85$.

9 Streda A. Shoulder joint changes in progressive polyarthritis. Rad Diagn 1964;6/4:409-19.

10 Pahle J A. The shoulder in rheumatoid arthritis. In: Lettin AWF, Petersson C, eds. Rheumatoid arthritis surgery of the shoulder. Rheumatology 1989;12:15-23.

11 Cuomo F, Greller MJ, Zuckerman JD. The rheumatoid shoulder. Rheum Dis Clin North Am 1998;24:67-81.

12 Crossan JF, Vallance R. The shoulder joint in rheumatoid arthritis. In: Bayley I, Kessel L, eds. Shoulder surgery. Berlin: Springer, 1982:131-8.

13 Kaarela K. Prognostic factors and diagnostic criteria in early rheumatoid arthritis. Scand J Rheumatol 1985 (suppl 57): $1-54$.

14 Larsen A, Dale K, Eek M. Radiographic evaluation of the rheumatoid arthritis and related conditions by standard reference films. Acta Radiol Diagn 1977;18:481-91.

15 Jones A, Watt I. Diagnostic imaging of the shoulder joint. Baillieres Clin Rheumatol 1989;3:475-510.

16 Bennet WF, Gerber C. Operative treatment of the rheumatoid shoulder. Curr Opin Rheumatol 1994;6:177-82. 